\title{
Employment of Gerontological Counseling Graduates: A Follow-Up Study
}

\author{
JANE E. MYERS \\ RICHARD H. BLAKE
}

\begin{abstract}
Twenty-five counselor education departments offering specializations in gerontological counseling were asked to survey their graduates who had completed course work or a specialization in aging. Implications are presented concerning employment opportunities for counseling graduates wanting to work with older people.
\end{abstract}

Interest and activity related to the counseling of older persons and the preparation of counselors for work with older people has been increasing. Support for this statement exists in several forms including the publication of instructional materials (Ganikos, 1979; Myers, 1981), books (Landreth \& Berg, 1980; Pulvino \& Colangelo, 1980; Keller \& Hughston, 1981), and special agingrelated issues of journals. (Sinick, 1976; Colangelo \& Pulvino, 1980; Ganikos, 1980; Myers, 1982; Myers \& Rimmer, 1982).

A study of counselor education activities related to the counseling of older persons conducted by the Association for Counseling and Human Development (ACHD) Committee on Adult Development and Aging in 1978 (Blake \& Brennan, 1978) found considerably more activity than had been reported by Salisbury (1975) just 3 years earlier. More recently Wantz, Sherman, and Hollis (1982) concluded from their survey of counselor education programs that increased gerontological counseling is a trend. They found that the number of course offerings had increased by 80 between 1977 and 1980 and the aged had increased as a target population from 1 percent in 1977 to 6 percent in 1980. Although this age group remains the least frequent target population age group, the increase is dramatic and substantial.

New courses in geriatric counseling have been developed in numerous counselor education programs. In fact, this area is second only to marriage and family counseling in terms of new course development nationwide (Hollis \& Wantz, 1983). The often cited Salisbury study (1975), which found the elderly to be a neglected target group in counselor education, is not descriptive of the current situation. In fact, a recent study by Myers (1983) reveals that 36 percent of counselor education departments now offer one or more courses to train counselors for work with older people.

A final indicator of interest in the counseling of older persons and in the preparation of persons for work with this special population is the recent creation of the Task Force on Adult Development and Aging within the Association for Counselor Education and Supervision, a division of ACHD.

Numerous work settings have been identified as appropriate for the counseling of older people. Some of these are traditional counseling settings; for example, the employment (Ganikos,
1980; Myers, 1980) and rehabilitation (Myers, 1981) services agencies. Others are more specifically older person-oriented and less traditionally thought of as employers of counselors; for example, area agencies on aging (Salmon, 1980) or nursing homes (Pressey \& Pressey, 1972). Schmidt (1976, p. 191) suggested that "counseling could be made available wherever the older person lives, works, engages in recreation, or receives some sort of treatiment."

There is no doubt that ACHD, several of its divisions, and an increasing number of counselor education programs are concerned with the provision of counseling services for older persons, the preparation of counselors for such work, and naturally the employment of counselors in positions that would enable them to provide the services for which they are increasingly prepared. But, to be interested and active in the preparation of counselors and the identification of suitable settings for work with older persons does not demonstrate that employment opportunities in fact exist or that counselors who receive special preparation for work with older people do work in such settings and with older people.

The purpose of this study was to determine whether or not counseling graduates with specialized gerontological preparation are, in fact, entering into the kinds of employment settings where they can work with older persons as clients. Few follow-up studies of counseling graduates or systematic studies of entry level employment patterns or needs have been published. Those published have tended to relate to new or special interest areas such as women in college student personnel work (Kuh, 1979) or undergraduate guidance majors (Berg \& Landreth, 1980; Schmitz, 1981). No previous followup studies of counseling graduates with gerontological training have been found in national journals. Apparently no "manpower projectives" on gerontological counseling have been made by any of the following agencies: the U. S. Administration of Aging, the National Institute of Mental Health, the National Association of State Units on Aging, or the National

Jane E. Myers is an assistant professor of Guidance and Counseling and director of Rehabilitation Counselor Education at Ohio University in Athens. Richard $H$. Blake is a professor in the Department of Counseling and Special Education at the University of Nebraska at Omaha. 
TABLE 1

Employers of Gerontological Counseling Graduates

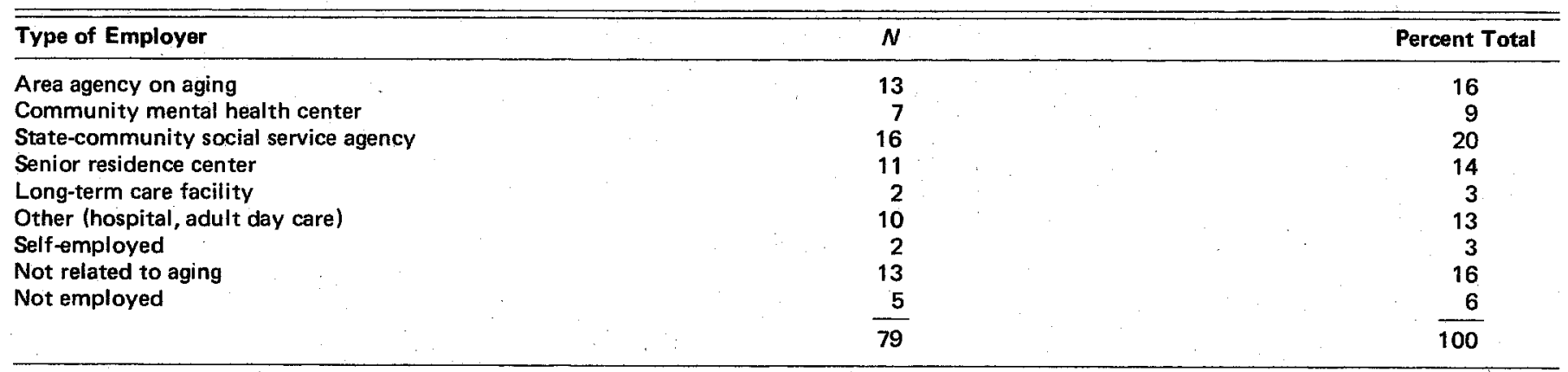

Association of Area Agencies on Aging (Barry, 1981). This follow-up study is a start towards better understanding of employment experiences and opportunities for counseling graduates in gerontology.

\section{METHODOLOGY}

Each of the 25 counselor education departments identified by Myers (1983) as having a specialization in gerontological counseling was mailed a questionnaire asking that they participate in this study. Each department was asked to survey their graduates who completed course work or a specialization in aging and who indicated an interest in working with older persons upon completion of their training. A supply of survey forms was included with the cover memorandum. Each department was asked to mail the form to their graduates, with instructions to return completed forms to the authors.

\section{RESULTS}

A total of 79 individual resources was returned, representing 14 different university programs. Because of the nature of the sampling, it was not possible to obtain an accurate count of the exact number of individual questionnaires mailed, hence it is not possible to report a rate of return. Several departments reported that, although their specialization had been established, they had not as yet graduated any students with a gerontology specialization; therefore, they were unable to participate in the survey. Some respondents failed to complete some of the items; so, the total number of respondents for each item to be discussed varies from the actual total of 79 questionnaires received.

Among those who responded, one person received their degree prior to 1970 , ( 1 percent); 3 between $1973-75$, (4 percent); 4 in 1976 ( 6 percent); 6 in 1977, (8 percent); 7 in 1978, (10 percent); 11 in 1979, (15 percent); 13 in 1980, (18 percent); 13 in 1981, (18 percent); 12 in 1982, (16 percent); and 3 expected to receive their degree in 1983 , (4 percent).

Seventy-two of 77 respondents ( 94 percent) indicated that they were employed, and 27 of these persons ( 35 percent) were already employed while in school. Twenty-one persons (27 percent) became employed within 1-2 months after graduation; 4 (5 percent) within 3-6 months; one ( 1 percent) in the 6- to 12 -month interim; 6 ( 8 percent) between 1 and 2 years after graduation, and 4 ( 5 percent) after 2 years.

The types of jobs in which the 79 persons were employed are shown in Table 1 . The wide variety of job titles and settings reported were classified into nine categories for purposes of analysis. These categories reflect the type of employer that provides a more accurate representation of the employment of graduates than would a reporting of the various job titles.

As can be seen from this table, a large proportion of the respondents are employed in settings that provide services exclusively to older people, including area agencies on aging and senior centers. Another large group is employed in social service agencies that also may serve persons of other ages.

Table 2 shows the percentage of the time respondents indicated spending in service to older persons. Almost half ( 47 percent) of the respondents spend between 76 and 100 percent of their time serving older persons. More than one-third of them (37 percent) reported spending less than one-quarter or 25 percent of their time serving older people. Seventeen percent of respondents provided no service to older clients as part of their job:

\section{DISCUSSION AND RECOMMENDATIONS}

The results of this study represent an initial attempt to learn about employment opportunities for counselors trained to work with older people. It is an essential first step to help educators and practitioners learn the available potential employment sites for persons trained in the new specialty of gerocounseling: Moreover, the presence or absence of available work sites is a significant issue affecting employment advocacy efforts within our profession. We are aware, especially in the area of aging, that other professions, notably social work, have been the traditional providers of services. To the extent that we are making inroads to employment in aging-related settings, we may assume the viability and necessity of the services provided by counselors.

\section{TABLE 2}

Percent of Jobs Spent in Service to Older Persons

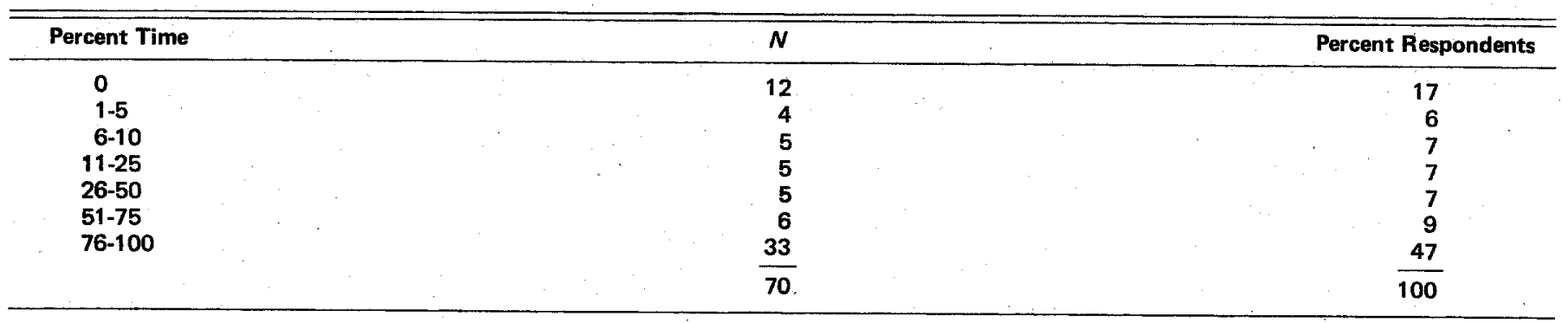


It is apparent from this study that the majority of our graduates obtain jobs soon after graduation. The fact that many were already employed while in school is an interesting finding. Perhaps, as happened to one of the authors, they found themselves working in settings where older persons were served but were lacking in the training needed to serve them effectively. Many adults return to school to learn skills required for their current jobs, as well as to prepare for future jobs.

The results indicate also that our graduates are working in jobs having variable amounts of contact with older people. The trend seems to be towards a great deal of contact with this client population. The implication here is that we are, in fact, training counselors with a needed specialization for the work force. And, as the results so vividly show, each year we are graduating increașing numbers of these persons. It is, therefore, encouraging to learn that many are obtaining employment congruent with their professional preparation and goals.

No firm conclusions regarding the degree of success counseling graduates are having in gaining employment in gerontological counseling can be reached from this study, nor can we be confident that the findings represent the actual distribution of work settings of gerocounselors. But three important conclusions can be made and the findings suggest some others. First, counselors are gaining employment in situations where a substantial portion of their time is spent working with older persons. Second, there is no single type of agency that dominates the employment pattern of gerocounselors. Third, gerocounselors have gained employment both in those types of agencies that provide services to persons of all ages and in programs that primarily serve older persons.

The findings suggest that community mental health centers are not employing gerontological counselors to the extent that might be expected; also, that long-term care facilities, which are generally required to have social workers, are still not turning to counselors to fill those positions. (It is known that social workers dominate that area of employment.) In general, the findings tend to support the expectations of the authors that gerocounselors are potentially employable in a wide variety of settings.

The accelerating rate with which counselor education programs are offering gerontological counseling courses and establishing gerontology as an area of specialization indicates an expectation that students will find employment related to that preparation. This study demonstrates that at least some graduates have done so and suggests that future graduates might also do so. But demographic trends and the needs of older people on the one hand and services for them on the other remain two very different things. The counseling profession and particularly counselor educators must assume that employment of graduates in gerontology will be subject to the same types of factors as employment in other service areas. Politics, economics, interprofessional competition and cooperation, traditions, laws, policies, and professional competence and image are all important. This study shows that employment can happen but certainly does not demonstrate a ready market for gerocounselors. Large scale employability in gero- counseling is a development of the future, if it is to exist at all. Our recommendation is that the profession attempt to expand employability of gerocounselors by working to influence all the factors that now restrict opportunities. We should work to make sure that the increase in aging courses and gerospecializations is matched by an increase in work opportunities.

The employment experience of past graduates is certainly not an adequate basis for future planning, though better than nothing. Employment opportunites, in addition to human needs and counselor interest, need to be considered by those contemplating entry into gerontological counseling and those planning training programs. Most counselors like to be paid for their good deeds. The likely work settings have direct implications for training, at least to those counselor educators who think preparation should be relevant to practice.

\section{REFERENCES}

Barry, J. (personal communication, March 21, 1983)

Berg, R., \& Landreth, G. (1980). Undergraduate majors, where are they now? A five-year follow-up. Counselor Education and Supervision, $19,177-181$.

Blake, R., \& Brennan, C. (1978). Preparing counselors for work with older people: A report to the APGA Adult Development and Aging Committee. Unpublished report.

Colangelo, N., \& Pulvino, C. (1980). Counseling the elderly. Counseling and Values, 24, 66-263.

Ganikos, M. (Ed.). (1979). Counseling the aged: A training syllabus for educators. Falls Church, VA: American Personnel and Guidance Association.

Ganikos, M. (Ed.). (1980). Work/life counseling for older people [Special issue] of Journal of Employment Counseling, 17.

Hollis, J. W. \& Wantz, R. A. (1983). Counselor preparation 1983-1985: Programs, personnel, trends. Muncie, IN: Accelerated Development.

Keller, J., \& Hughston, G. (1981). Counseling the elderly. New York: Harper \& Row.

Kuh, G. (1979). Entry-level employment prospects for women in collegestudent personnel work. Personnel and Guidance Journal, 57, 296-297.

Landreth, G., \& Berg, R. (1980). Counseling the elderly. Springfield, IL: Charles C Thomas.

Myers, J. E. (1980). Counseling the disabled older person for the world of work. Journal of Employment Counseling, 17(1), 37-48.

Myers, J. E. (Ed.). (1981). Rehabilitation of older persons [Special issue]. Journal of Rehabilitation, 47(4), 8-95.

Myers, J. E. (1983). Gerontological counseling training: The state of the art. Personnel and Guidance Journal, 61 (7), 398-401.

Myers, J. E., \& Rimmer, S. (Eds.). (1982). Assessment and older persons [Special issue]. Measurement and Evaluation in Guidance, 1.5 (3).

Pressey, S., \& Pressey, A. (1972). Major neglected need opportunity: Old age counseling. Journal of Counseling Psychology, 19, 362-366.

Pulvino, C., \& Colangelo, N. (1980). Counseling or the growing years: 65 and over. Minneapolis, MN: Educational Media Corporation.

Salisbury, H. (1975). Counseling the elderly: A neglected area in counselor education. Counselor Education and Supervision, 14, 237-238.

Salmon, H. (1980). A comprehensive strategy for offering guidance and counseling services to older adults. Counseling and Values, 24, $210-217$.

Schmidt, L. (1976). Issues in counseling older people. Educational Gerontologist, 1, 187-192.

Schmitz, C. (1981). Baccalaureate programs in counseling: Follow-up and implications. Counselor Education and Supervision, 21, 16-21.

Sinick, D. (Ed.). (1976). Counseling over the life span [Special issue]. Personnel and Guidance Journal, 55(3).

Wantz, R., Sherman, A., \& Hollis, J. (1982). Trends in counselor preparation: Courses, program emphasis, philosophical orientation, and experiential components. Counselor Education and Supervision, 21, 258268. 